\title{
Four-Year Experience with Methotrexate Exposures
}

\author{
Frank LoVecchio, DO, MPH ${ }^{a}$, Kenneth D. Katz, MD ${ }^{b}$, David J. Watts, $\mathrm{MD}^{c}$, Ian O. Wood, DO
}

aBanner Good Samaritan Regional Poison Center, Maricopa Medical Center, Department of Emergency Medicine, Phoenix, AZ

bUniversity of Pittsburgh Medical Center, Department of Emergency Medicine, Pittsburgh, PA

'St. Luke's Hospital, Department of Emergency Medicine, Bethlehem, PA

dMaricopa Medical Center, Department of Emergency Medicine, Phoenix, AZ

\section{ABSTRACT}

Introduction: Unintentional methotrexate (MTX) acute oral overdose is rarely reported.

Methods: We conducted a retrospective chart review of all human exposure calls ( $>150,000$ charts) for MTX ingestions reported to our Poison Center during 2000-2003.

Results: Thirteen patients met the criteria. The average amount of MTX ingested was $13.03 \mathrm{mg}$ (data from 7 cases), and the average patient age was 43 years (20 months to 80 years). No significant toxicities occurred.

Discussion: Although intravenous MTX toxicity can be severe, this does not appear to be a phenomenon associated with either acute unintentional or suicidal oral ingestion.

\section{BACKGROUND}

Methotrexate (MTX), a folic acid analogue and antagonist, is used in the treatment of particular cancers, autoimmune diseases, placenta accrete and ectopic pregnancy. MTX interferes with the conversion of dihydrofolate to tetrahydrofolate, the primary carbon donor for purine and pyrimidine synthesis, by inhibiting dihydrofolate reductase. Consequently, DNA and RNA synthesis disrupts, particularly in rapidly proliferating cells, such as cancer or immune cells [1]. Unfortunately, the effects of MTX extend to otherwise healthy normal cells, resulting in toxicity.

Toxicity following intravenous (IV) MTX therapy can be life threatening. Respiratory, hepatic, renal, neurological and hematological organ systems may be adversely affected. Interstitial pneumonitis, stomatitis, esophagitis, gastrointestinal bleeding, hepatitis, renal insufficiency, ataxia, paraplegia, nerve palsies and pancytopenia are well described more commonly with chronic toxicity [2]. Treatment with urinary alkalinization and leucovorin rescue is usually necessary to salvage normal healthy cells after high-dose IV MTX therapy [3].

MTX toxicity and outcomes following acute oral overdose, unlike IV toxicity, is ill defined. In this case series, we attempt to describe the clinical manifestations following acute oral MTX ingestion.

\section{METHODS}

We conducted a retrospective chart review of all human exposure calls ( 150, 000 charts) for MTX ingestions reported to our Poison Control Center (PCC) during the years 2000-2003. Inclusion criteria were any acute oral MTX ingestions in human beings, irrespective of age, referred to our PCC. Chart review was conducted using Crystal Reports (Visual Dot Lab Enterprise, WBM Software, Fresno, CA). The only exclusion criterion was the inability to meet the inclusion criteria.

Keywords: methotrexate, poisoning, toxicity, oral

Notes: Previous presentation at North American Academy of Clinical Toxicology Annual Meeting, September 2003, Chicago, IL There was no outside funding of any kind used for this study.

Corresponding Author: Frank LoVecchio, DO, MPH, Maricopa Medical Center, Department of Emergency Medicine, 2601 E. Roosevelt St., Phoenix, AZ 85010 Email: Frank.LoVecchio@bannerhealth.com 


\section{RESULTS}

Thirteen patients met the inclusion criteria. The average amount of MTX ingested was $13.03 \mathrm{mg}$ (data from 7 cases), and the average patient age was 43 years (range 20 months to 80 years). The most common formulation ingested was the 2.5-mg tablet. Eleven patients unintentionally ingested MTX, and two admitted suicidal MTX ingestion.

The 2 suicidal patients also had benign co-ingestions. One patient ingested three 600-mg ibuprofen tablets and the other ingested $2 \mathrm{~g}$ of acetaminophen. Neither patient had any symptoms. These patients were admitted, with one receiving leucovorin, and each had MTX levels drawn $(0.09 \mu \mathrm{mol} / \mathrm{L}$ and $0.47 \mu \mathrm{mol} / \mathrm{L}$, respectively; therapeutic $<10 \mu \mathrm{mol} / \mathrm{L})$. Both were completely asymptomatic without demonstrable hepatic or hematological toxicity at 48 hours. No symptoms were noted 4 days postingestion. The rational for the administration of leucovorin in one case was related to the inability of the institution to check a MTX level in a timely fashion.

Of the 11 unintentional MTX ingestions, 10 were observed at home with PCC follow-up for 24 hours, all with excellent outcomes. One patient with unintentional MTX ingestion was observed in the emergency department for 4 hours and discharged without incident. A level was not available until the next day. The 4 pediatric patients ( 3 unintentional, 1 suicidal) all did well. Only 1 patient (suicidal) received leucovorin rescue, and only 2 had MTX levels drawn (2 suicidal). No patient had known renal insufficiency.

\section{DISCUSSION}

The potentially life-threatening effects of toxicity from chronic exposures of MTX are documented in patients receiving IV or parenteral treatment. In this case series, we analyzed possible acute MTX overdose after oral ingestion. Our findings suggest that oral ingestion of MTX is associated with little toxicity. These data are supported by previous reports of unintentional oral MTX administration without significant sequelae. Stephen et al. (1994) described treatment of a 2-year-old child with activated charcoal who was suspected to have ingested 100 2.5-mg MTX tablets; the child did not develop toxicity [4]. Similarly, 3 children unintentionally ingested MTX and demonstrated only transient elevations in liver enzymes, but no life-threatening sequelae $[5,6]$. In 1991, an 80-year-old woman was reported to have mistakenly ingested $10 \mathrm{mg}$ of MTX for 4 consecutive days, resulting in mucositis, fever and pancytopenia but, again, no long-term injury [7]. Chronic overdose can result in death [8,9].

Oral ingestion of MTX results in little toxicity. This may be attributable to the pharmacodynamics of MTX and the relatively smaller amount of MTX prescribed for outpatient therapy. First, both the total amount and the length of exposure to MTX are correlated with an increased risk of some adverse events, such as bone marrow suppression, hepatic toxicity, and renal insufficiency. Oral absorption appears to be dose dependent. At doses $<30 \mathrm{mg} / \mathrm{m}^{2}$, MTX is generally absorbed with a mean bioavailability of about $60-70 \%$. However, at doses approaching $80 \mathrm{mg} / \mathrm{m}^{2}$, absorption is as low as $20 \%$, most likely due to enzyme saturation $[8,9]$.
As a result, larger oral doses do not directly correlate with respective increases in serum levels, thereby prohibiting toxic levels $(>10 \mu \mathrm{mol} / \mathrm{L})$. Second, in the outpatient setting, MTX dosing is much lower than that of IV administration. While treatment regimens vary, the most common oral MTX formulation is $2.5-\mathrm{mg}$ tablets prescribed in amounts which make it difficult to unintentionally or intentionally ingest enough drug to result in toxicity. Incidentally, one of the patients in our report received leucovorin therapy, which was probably unnecessary in hindsight.

Shortfalls of this study include the paucity of serum MTX concentrations and unsubstantiated ingested amounts in all of the cases. Delineation of these 2 variables would afford a clearer determination of the association between acute, dose-dependent responses and blood levels of MTX. Another limitation is the relatively small number of patients, which precludes any definitive conclusions regarding the relationship of oral dosing and serum levels resulting in toxicity.

In summary, in our small case series, patients followed for 24 hours after reporting potential exposure to acute MTX did not manifest significant toxicity during that period. The cases presented indicate that acute oral ingestion of MTX, either unintentional or intentional, is not associated with severe toxicity. Rather, it results in little if any toxicity and typically does not require leucovorin rescue. Although supported by a few previous reports, information regarding oral MTX and toxicity remains scarce. More studies to better substantiate the relationship between oral MTX ingestion and toxicity are encouraged.

The authors have no potential financial conflicts of interest to report.

\section{REFERENCES}

1. Cronstein BN. The mechanism of action of methotrexate. Rheum Dis Clin North Am 1997;23(4):739-755.

2. McKendry RJ. The remarkable spectrum of methotrexate toxicities. Rheum Dis Clin North Am 1997;23(4):939-954.

3. Poisindex Toxicologic Management: Micromedex, Inc., Vol. 87, 1996.

4. Stephen M, Snook C, Bausher J: Pediatric methotrexate ingestion: A case report. Vet Hum Toxicol 1994;36(4):366.

5. Pruitt AW, Kinkale JM, Patterson JH: Accidental ingestion of methotrexate. J Pediatr 1974;85(5):686-688.

6. Gibbon BN, Manthey DE. Pediatric case of accidental oral overdose of methotrexate. Ann Emerg Med 1999;34(1):98-100.

7. Brown MA, Corrigan AB: Pancytopenia after accidental overdose of methotrexate. Med J Aust 1991;155(7):493-494.

8. Sinicina I, Mayr B, Mall G, Keil W. Deaths following methotrexate overdoses by medical staff. J Rheumatol 2005; 32(10):2009-2011.

9. Tracy TS, Worster T, Bradley JD, Greene PK, Brater DC. Methotrexate disposition following concomitant administration of ketoprofen, piroxicam and flurbiprofen in patients with rheumatoid arthritis. Br J Clin Pharm 1994;37:453-456. 